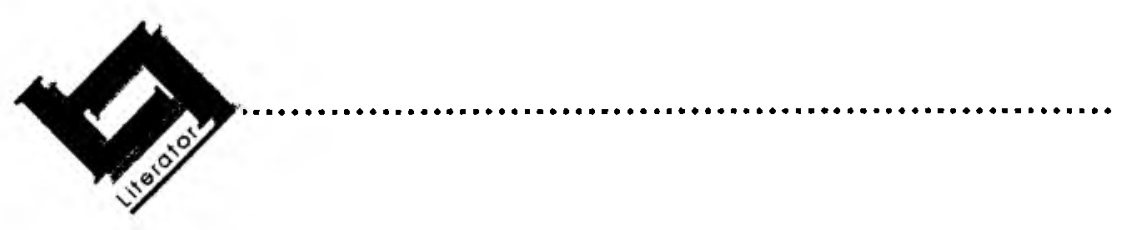

\title{
Die Afrikaanse poësie vir kykers ${ }^{1}$
}

\author{
Jacques van der Elst \& Chrissie Reinecke \\ Fakulteit Lettere \& Wysbegeerte \\ Potchefstroomse Universiteit vir $\mathrm{CHO}$ \\ Potchefstroom \\ E-pos: dlwjvde@puknet.puk.ac.zo
}

\begin{abstract}
Atrikaans poetry for viewers
\end{abstract}

The purpose of this article is to create an awareness of the visual or socalled physiognomic aspects of poetry in Afrikaans. Several examples of Afrikaans poems with a visual presence are given. Visuality in poetry is not a new phenomenon. It is of course linked to the emergence of concrete poetry which was formally named thus by Eugen Gomringer and Decio Pignatari in 1955. A fully-fledged and complete volume of concrete or visual poetry in Afrikaans was created by Willem Boshoff during the seventies and published in 1980. The physiognomically striking Afrikaans poems can be classified and studied according to the physical size of the visual element responsible for the overall impact of the poem. Several forms of these elements and their impact on the relevant poems are discussed in this article, which is based on an exploration of more than 500 volumes of poetry, in order to get an overview on visuality in Afrikaans poetry from the beginning of this century until 1989.

1 Die materiaal vir hierdie artikel is hoofsaaklik ontleen aan die proefskrif van dr. Chrissie Reinecke, getitel Fisionomiese opvallende gedigte in Afrikaans (1991) met proff. J. van der Elst en M.C.A. Seyffert, onderskeidelik promotor en medepromotor. 


\section{Inleidend ${ }^{2}$}

Agter op die buiteblad van Willem Boshoff (1980) se Kykafrikaans verskyn die volgende "teoretiese geskrif":

Soggens vroeg en saans laat, in sy oorskiettyd, so te sê, maak Willem Boshoff, 'n skrywerseun, weggooigoed bymekaar, ondermeer, onder báie meer, taalafval. Wat hy die afgelope drie jaar opgetel het, staan in hierdie boek. Is dit visuele poësie, konkrete digkuns, lettrisme of tekenverse? Willem weet nie. Wie wil ook weet as dit so lekker is om na Afrikaans te kyk.

Die weggooigoed in die boek is nie die enigste Afrikaans waarna 'n mens graag kyk nie. In Afrikaanse digbundels en tydskrifte is daar lankal heelwat "kykgedigte" waaroor dieselfde vrae as hierbo gevra kan word. Natuurlik is daar die nuuskieriges - binne die konteks van die navorsing, die literatuurwetenskaplikes - wat antwoorde op dié vrae wil hê.

Ander vrae kan bygevoeg word. Waarna word presies gekyk? Moet daar op ' $n$ bepaalde manier daarna gekyk word? Wat is die funksie van die dinge wat die aandag van die oog opeis? Daar sou ook oor die verhouding tussen kykdinge en die ander elemente van die gedig besin kon word. Is dit die moeite werd om na die gedigte te kyk, is dit regtig "lekker", soos wat Willem Boshoff beweer? Vorm die kykgedigte dalk 'n subgenre in die Afrikaanse digkuns? Waarom het hulle hulle verskyning gemaak? Vorm hulle deel van 'n literêre tendens of selfs 'n stroming, of is hulle slegs geisoleerde eksperimente? Binne die bestek van hierdie artikel word slegs enkele van hierdie vrae beantwoord.

Studies oor die Afrikaanse letterkunde bied geen deurtastende en sistematiese antwoorde nie, terwyl die bewustheid van kykpoësie in die Afrikaanse literatuurkritiek maar beperk is. In anderstalige gedigte is soveel kykverrassings ontdek, dat 'n mens verbaas is oor die verwaarlosing van die sogenaamde kykgedig in Afrikaans.

Op grond van uitgebreide navorsing (Reinecke, 1991:2-5) oor die sogenaamde konkrete poësie word die kykgedigte in Afrikaans, ook die taalafval van Boshoff, fisionomies opvallende gedigte genoem. Konkrete

2 Die aard van die artikel is sodanig dat na baie visuele eienskappe van gedigte venws word. Visualiteit is soms moeilik reproduseerbaar - lesers word aangeraai om seff die verwysings in die oorspronklike bundels na te slaan. 
poësie en sy verwante vorme bied 'n bruikbare verwysingsraamwerk vir die studie van die aard van kykgedigte in Afrikaans.

\section{Fisionomie}

Die betekenis van die woord fisionomie word in WAT (1955:699) soos volg verduidelik:

1. Uitsig of aansien van ' $n$ mens of ander lewende wese as uitdrukking van inneriike welsyn en gesondheid; i.d besonder, menslike gelaatstrekke en gesigsvorm beskou as uitdrukking van iem. se karakter en aard; gelaatsuitdrukking; by uitbr., iem. se gelaat in die algemeen. 2. Algemene voorkoms, uiterlike aansien; innerlike aard of hoedanigheid soos uiterlik geopenbaar ... Die fisionomie van 'n politieke party, 'n kultuur, 'n kunswerk.

HAT (1979:167) vat die kern van die betekenis soos volg saam: "Gelaat; uiterlike voorkoms - veral as uitdrukking van karakter."

Vir die doel van die artikel word die fisionomie van die gedig beskou as alles wat die gedig materieel konstitueer en wat visueel waargeneem kan word: van die tipografie tot die vorm en die aard van die materiaal waarop die teks gedruk of geskryf is. Die fisionomie word dus hoofsaaklik deur die visualiteit van die gedig bepaal.

Die term fisionomie is nie vreemd in die literatuur oor die materieel visuele eienskappe of die visualiteit van die poësie nie. De Vree (1981:1) praat van die "fysionomische typografie" as hy oor Van Ostaijen se gebruik van die grafiese ruimte in die poësie skryf; Pignatari (1982:190, 191) sê dat Cummings die "physiognomic peculiarities" van bepaalde letters ontgin, terwyl "physiognomic resources" in konkrete poësie benut word; Clüver (1982:147) onderskei 'n "physiognomic-organic phase" in die ontwikkeling van die Brasiliaanse konkrete poësie.

Wanneer 'n gedig fisionomies opvallend is, sal die materiële visualiteit van so ' $n$ aard wees dat dit die oog onmiddellik vang en vashou. Visuele opvallendheid word veral deur twee faktore bewerkstellig:

- die andersoortigheid van 'n verskynsel binne 'n bepaalde omgewing;

- inherente visueel opvallende eienskappe.

\section{Konkrełe poësie}

Van ongeveer die begin van die eeu, maar veral sedert die vyftigerjare, het daar in wêrelddele so ver uitmekaar soos Latyns-Amerika, Switserland en Japan 'n poësie ontwikkel wat as konkrete poésie bekend 
geword het. Die Boliviaans gebore Switser Eugen Gomringer en die Brasiliaan Decio Pignatari het tydens 'n ontmoeting te Ulm in 1955 formeel op dié term besluit.

Konkrete poësie word die maklikste aan die opvallendheid van die materieel konkrete eienskappe van die gedig herken. Brems (1984:182) verduidelik die werkwyse van ' $n$ aantal Nederlandse en Vlaamse digters van konkrete poësie: "Ze brengen allemaal eigen varianten aan en leggen klemtonen in een poëzie, die concreet is in die zin dat ze gebruikt maakt van datgene wat zintuiglijk concreet is aan de taal, nl. klank en/of vorm van de woorden of letters." Konkrete poésie dui dus op die gedigelemente wat gesien en gehoor kan word.

Die onderliggende dryfveer tot die opvallende visualiteit en/of akoestiek is ook die essensie van konkrete poësie: die bewuste waarneming van die materiaal en die struktuur van die gedig (De Vree, 1970:9; 1971:486). Die materialiteit van die teks speel inderdaad so ' $n$ belangrike rol dat dit nie net as 'n beklemtoning of ' $n$ konkretisering van die verbale uitbeelding gesien moet word nie.

Taylor (1985:231) stel dit soos volg: "For concretists do not argue, generally, that highlighting the materiality of the text provides a sensory equivalent for verbal imagery. More often, they see visual dimension itself, the material text, as securing concrete effects."

Fisionomie speel eintlik in alle gedigte ' $n$ rol. Daar is egter gedigte met 'n opvallende en/of 'n dominante fisionomie. Dit moet beklemtoon word dat die visualiteit waaroor dit hier gaan, die materieel konkrete visualiteit van die teks is. Dit sluit die beeldgedig wat deur Jonckheere (1989 en 1990) ondersoek is, uit. Laasgenoemde kan kortweg as die herskepping van 'n beeldende kunswerk in taal beskryf word.

\section{Enkele fisionomies opvallende gedigte in Afrikaans}

Daar is nog geen omvattende en sistematiese navorsing oor Afrikaanse gedigte met 'n opvallende fisionomie onderneem nie, veral nie van gedigte waarvan die fisionomie dominant is nie.

Één aspek van fisionomie is wel erken. Bykans drie dekades gelede skryf Geggus (1961) 'n proefskrif met die titel: "Die wit in die poësie". Sy gaan van die standpunt uit dat die anormale hoeveelheid wit in die visuele aanbod van die poësieteks 'n onderskeidende kenmerk van die poësie is. Geggus (1961:23-24) baken haar studieveld baie nadruklik af. Sy sê dat sy haar "nie besig hou met sogenaamde eksperimentele poèsie waar selfs die tipografie in die eksperiment betrek is en die wit 
gevolglik in 'n hoë mate opvallend word nie." Later sê sy weer: "Ons beklemtoon dus nog ' $n$ keer dat ons ons bepaal by poësie wat in sy visuele aanbod nie afwyk van die klassiek-tradisionele of konvensionele drukbeeld van poësie nie - met ander woorde: poësie sónder tipografiese buitensporighede." Die poësie wat Geggus uitsluit, vorm juis die kern van hierdie ondersoek. Die gedigte wat sy bestudeer, lê op die periferie van die ondersoekveid.

Geggus (1961:25) is nie baie simpatiek teenoor fisionomies opvallende gedigte nie. Vir haar is die soort gedigte "verteenwoordigers van 'n soort uitloper of 'n sy-tak van die poësien".

In een van Afrikaans se heel vroegste visuele tekste, naamlik die vaasvormige eerste strofe van "Die rose van herinnering" van A.G. Visser (1927:9-10), sien Dekker (1965:x) 'n "liefde vir die spel van die fraaie vorm". Vir hom is dit tekenend van Visser se sogenaamde ondiepsinnige poësie.

Cloete (1980:120-121) gebruik wel die term "konkretisme" as 'n kenmerk van die sestiger- en sewentigerpoësie, maar hy koppel dit hoofsaaklik aan die belewing van die konkrete werklikheid, dikwels 'n sintuiglike werklikheid, asook aan die taalgebruik, wat 'n spreektaligheid is. Enkele name van digters wat tog in hierdie verband na vore kom, is Knobel, Rowland, Breytenbach, Weideman, Opperman en Krog.

Visuele poësie word ook as 'n vorm van vernufpoësie beskou (Hugo, 1988:60-73). Daar word op die "sigwaarde" van die letters in "Tieners en sedertdieners" van D.J. Opperman (1964:40) gewys, op die "tipografiese eksperiment" in "Safari" en "Lampe langs die pad" van D.J. Opperman (1964:9 en 1979:83-84, onderskeidelik) en op die ikonisiteit van "wit spasies" in "ek wag in my hart" van Breyten Breytenbach (1964:68). Hugo meld dat Kykafrikaans van Willem Boshoff (1980) die enigste bundel visuele poësie in Afrikaans is en haal "Tussen hemel en aarde" (Boshoff, 1980:37) as ' $n$ voorbeeld van 'n "ikoniese vers" aan. Ten slotte word visuele poësie gesien as een van die fasette van die "tweeledige verskynsel konkrete poësie".

Oorsigtelik kan afgelei word dat, afgesien van Hugo (1988) se erkenning van visuele poësie, die idee van die oonwig aan 'n opvallende of ' $n$ dominante fisionomie in die gedig nog vreemd in die poësiekode van die Afrikaanse tradisie is.

Uit 'n ondersoek (Reinecke, 1991) na opvallende visuele kenmerke van gedigte in meer as 500 Afrikaanse digbundels blyk duidelik dat 'n verskeidenheid visuele middele gebruik word, kennelik in navolging van 
die sogenaamde konkrete poësie wat nie altyd bewus nie, maar miskien tog onbewus nagevolg is. Konkrete digters is naamlik die grootmeesters van die visualiteit en buite die Afrikaanse poësie hoef ' $n$ mens nie ver te soek nie om digters soos Paul van Ostaijen en Theo van Doesburg as skeppers van kykgedigte of fisionomies opvallende gedigte te identifiseer nie.

\subsection{Enkele kategorieë van fisionomiese vooropstelling in Afrikaanse gedigte}

Van die kleinste eenheid in die gedig tot groteres word benut om benewens die belewenis van die leesaksie ten opsigte van die gedig, ook die kykaksie te verhoog. 'n Mens kan onder meer praat van die gebruikmaking van nie-fonologiese skrifstelsels.

'n Kategorie visuele verskynsels wat byvoorbeeld in die poësie benut word, is die piktogram, die ideogram, die hiëroglief en die logogram.

'n Voorbeeld van 'n piktogram kan gevind word in Joan Hambidge se gedig "The man whose pharynx was bad" (1987:54). Die piktogram kom voor in die slotstrofe, verder beklemtoon deur die letters in vetdruk.

\section{THE MAN WHOSE PHARYNX WAS BAD}

Oor die borrelbruin

van ervarings

the malady of the quolidian ...

raak mens melancholies,

Mr. Burton.

Melancholie?

Vervloekte woord!

Woorde nuttelose prutsels ...

Poësie?

Oorbodige selfbewuste aksie!

Want:

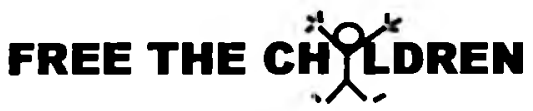

Hieraan kan woede

niks doen; woorde

wil ook nie bevry - 
Die aanklag word in die gedig gemaak dat die modeme woord, dit wil sê ook die poësie, "nuttelose prutsels" geword het wat niks aan die nood van kinders (aangehou in 'n vorige politieke bestel?) kan doen nie. Daarom word van 'n piktogram, 'n staafmannetjie, met sy direkte visuele appèl gebruik gemaak om die nood te beklemtoon. Die visuele plasing van die piktogram binne die groot, vetgedrukte versreël dui daarop dat die kind eintlik deur woorde vasgedruk word. Die woord/woorde is magteloos om te bevry.

In "Ballade" (1987:17) maak Hambidge weer gebruik van 'n ideogram. Dit geld ook Opperman (1979:94-95) se gedig "Gesponste lei", waar hy 'n eie ideogram skep om die konvensioneel onverwoordbare dinge met 'n knipoog in 'n ander "taal" te suggereer. Die ideogram in die hierby afgedrukte vyfde en voorlaaste strofe van die gedig is saamgestel uit die ideografiese komponent(die pyltjie) wat rigting aandui en die piktografiese teken wat na die manlike geslagsorgaan verwys. Dit is eintlik 'n kantlynillustrasie om te verseker dat die "stokki" in die volksrympie reg geinterpreteer word: die "ek" word weer seksueel lewenskragtig - hoewel die teruggang na 'n nulpunt eweneens in die piktografiese teken gesuggereer word.

\section{bok bok}

waarom staan

my stokki styi $\rightarrow(0$

Phil du Plessis gebruik weer in sy bundel Geskrifte om 'n houtgesig (1971) in die gedig "Menkheperre" (1971:66) 'n hiëroglief. Crystal (1987: 199) wys daarop dat hoewel hiërogliewe 'n piktografiese indruk skep, hulle in der waarheid uit drie simbole saamgestel is om woorde te verteenwoordig:

- ideogramme wat, soos uit die voorgaande blyk, na entiteite of idees in die werklikheid verwys;

- fonogramme, wat na een of meer konsonante verwys, baie soos die beeldraaisels (sg. rebusse) (vgl. Grobbelaar en Jordaan 1980:27);

- determinatiewe ("determinative") simbole, wat geen fonetiese waarde het nie, maar wat langs ander simbole geplaas word om tussen woorde, wat andersins dieselfde betekenis sou hê, te onderskei. 


\section{Menkheperre}

(son, huis, skarabee)

'n laaste komeetvlug word verseker:

lig vloei uit donkerte

wat oor die wêreldvloed broei om die siklus te begin

lewe kristalliseer weer uit die tuiste van reënvlerke

die ontliggaamde gloed van oggend en aand

vorm 'n liggaam van vlees om te weet:

die oog moet behou word

dat lig filtreer

die suiwerende delta van wete in

lig op water begin die kringloop

om weer eens 'n naam te vorm:

\section{O世⿻上丨) Menkheperre}

om te verduur is die wording van 'n songod

Om hiërogliewe te interpreteer, is meesal moeilik. Deur die leidrade in Phil du Plessis se gedig sover as moontlik te volg, kan daar afgelei word dat die hiëroglief verwys na die naam van die songod. Dit word deur die determinatief, die sirkel met die kolletjie, aangedui. Vervolgens is daar die skarabee, 'n soort miskruier, heel regs wat die Egiptenare gesien het as "' $n$ simbool ... van die son, wat deur een of ander geheimsinnige god oor die uitspansel gerol word" (Sauer, 1982:195). Die middelste simbool, wat volgens die onderskrif by die titel "huis" beteken, verteenwoordig " $m-n$ ". Verskeie name waarin hierdie kombinasie voorkom, kon nagespoor word. Menkent is byvoorbeeld "de ster O Centauri, van het sterrenbeeld de Centaur” (Anon., 1976:168). Oor Alfa Centauri sê Cillié (1981:202) dat dit die helderste van die Twee Wysers na die Suiderkruis is. Hy gaan voort: "Dit bestaan uit twee heldergeel sterre, wat 81 jaar nodig het om hulle omloop om mekaar te voltooi". Dié beskrywing herinner aan die "kringloop" in die gedig.

'n Onbekende persoon of 'n god se "wording" word in die gedig beskryf. Die hiëroglief self is die resultaat van die skrif ("kringloop" ook letterlik verstaan) van lig op water (strofe vier). Om die skrif te interpreteer ("die suiwerende delta van wete in"), is die verwerking ("filtreer") deur die oog 
onontbeerlik (strofe drie). Die ordenende rol van die oog is die rede waarom Taylor (1985:92) so op visuele geletterdheid aandring: as 'n mens weet hoe die oog die visuele poësie filtreer, sal jy dit des te beter kan verstaan en beskryf. Die lig waarvan daar telkens gepraat word, kom van die komeet af waarvan daar in versreël een gepraat word. Deur kantlynhegting word die eerste vers aan die laaste vers verbind sodat 'n mens kan sê dat die "laaste komeetvlug" aan die "wording van 'n songod" gelyk is. Die hiëroglief wat deur die lig gevorm word, is dus 'n goddelike lig.

Die gedig bevat ' $n$ poëtika oor die assosiasie van 'n bonatuurlike mag met skrif en uiteindelik met die poësie. Die hiëroglief ondersteun hierdie tema.

Logogramme word weer meesal in wetenskaplike notasies aangetref, byvoorbeeld in die logika en die wiskunde. Voorbeeide van logogramme is " $-", " x ", "<"$, " >", ensovoorts.

Daar is gedigte in Afrikaans waarin logografiese tekens fisionomies opvallend optree in die omgewing van die fonologiese skrifstelsel van die Afrikaanse poësie. Dit is dus veral wetenskaplike notasies wat ingespan word. Die gebruik van wiskundige simbole is 'n nalatenskap van die futuriste Dit was deel van hulle strategie om die tegnologiese eeu te verower. 'n Chemiese notasie som die prosesse in "Tygerberg" van D.J. Opperman (1979:65-66) op, terwyl wiskundige simbole die essensie in "taalwetenskaplikes" van Pieter Smit (1977:23) saamvat. In "rubrikator" en in "miniature" van T.T. Cloete (1985:21-22 en 23-28 onderskeidelik), word die strofes en hulle variasies genommer. Diegene wat T.T. Cloete as literator ken, sal weet hoe belangrik hy dit ag dat daar gedurig in die literatuurstudie getel moet word. Met behulp van ander visuele hulpmiddels (hooflettergebruik, leestekens, wat eintlik rekenaarsimbole word, en die ruimtelike organisasie) word die ontnugtering in "lanseerprogram: Apollo 1" van Carl Mischke (1984:51) in 'n rekenaarprogram gevisualiseer.

Die gebruik en funksie van logogramme word hier met behulp van "Tygerberg" nader toegelig. 


\section{Tygerberg}

Diederik Johannes Opperman

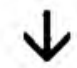

Pype, kabels, drade, naalde, strale

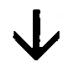

Hart, skedel, niere, lewer, longe

oë, ore, neus, blaas, sternum

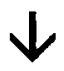

Wysernaalde, grafieke, plate, distillate
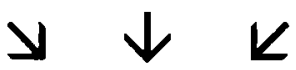

Kenner elk op sy gebied

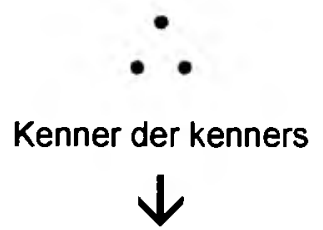

,Hy sterf'

"Tygerberg" (1979:65-66) kom uit die "Vierde Rol" van Komas uit 'n bamboesstok. Te midde van die oorweldigende gunstige resepsie van die bundel word daar relatief min aandag aan dié gedig gegee. Die enigste verwysing wat opgespoor kon word, is waar Greyling (1979:1) "Tygerberg" as voorbeeld van die talle siektebeelde en verwysings na medisyne en mediese dinge in die bundel noem.

In die eerste strofe (hierbo afgedruk) word die pasiënt, D.J. Opperman, wat skynbaar in die Tygerberg Hospitaal op sterwe lê, beskryf. Die tweede, die derde en die vierde strofe bevat die direkte woorde van 'n onsimpatieke persoon, waarskynlik 'n matrone, wat in 'n argument met mev. Opperman gewikkel is. Die persoon is baie ergerlik oor die aanhoudende getorring van mev. Opperman oor die voedsel wat haar man 
moet inneem en verwyt haar dat sy hom nie jare gelede van die drank losgekry het nie. Sy moet hom dus nou maar huis toe neem en self versorg.

Wat onmiddellik in die gedig opval, is die pyltjies in die eerste strofe. Hulle kan algemene indeksikale tekens wees wat rigting aandui, maar terselfdertyd ' $n$ ikoniese afbeelding van die netwerk pypies waaraan die pasiënt gekoppel is. Met die tekens wat in die teks opgeneem is, is daar ook die suggestie van 'n saaklike wiskundige konklusie wat net tot een punt kan lei, naamlik die slotversreel van die eerste strofe: "Hy sterf". Sterwe is weer 'n proses van ontbinding, dus van 'n chemiese reaksie, wat eweneens in die tekenspel van die gedig gesuggereer word. Die pyltjies kan dus ook deel van 'n formule wees wat 'n chemiese reaksie, 'n metamorfose van stowwe aandui. Dié interpretasie word deur die intertekstuele verband met die Glaukus-mite versterk. Volgens Malan (1986: 104) word die mite in Komas uit 'n bamboesstok gebruik om die bewustelose toestand van die digter uit te beeld en om die motief van gedaanteverwisseling of metamorfose te steun. Die intertekstualiteit blyk duidelik uit ' $n$ kort opsomming van Malan (1986:104) se oorvertelling van die mite. Nadat Glaukus grasspriete geëet het, spring hy in die see. In opdrag van die gode dra hy 'n spreuk nege maal voor en was hy homself in honderd riviere. As hy bykom, het hy in 'n onsterflike waterwese verander.

Wat verder in die fisionomie van die gedig opval, is die simmetriese bou van die eerste strofe teenoor die wisselende verslengtes van strofes twee, drie en vier. Die strak lyne wat deur die pyltjies gevorm word, dra by tot die onpersoonlike, gevoellose sfeer wat opgeroep word deur die opnoemtegniek, die argaiese "kenner der kenners" en die wiskundige of chemiese notasie. Die groot pyl van die geheelbeeld suggereer die onafwendbaarheid van die sterwensproses.

\subsection{Letters en variantvorme daarvan}

Die benutting van ideogramme, piktogramme, logogramme en hiërogliewe is slegs 'n klein onderdeel van die reekse visuele gereedskap wat in die Afrikaanse poësie aangewend word.

So is daar ook handgeskrewe gedigte soos dié van Johan van Wyk met sy "na 'n vorm van Apollinaire" (1976:25) en "KONKRETE POëZIE" van Barend Toerien (1983:17).

'n Verskeidenheid letterdruktipes word ook gebruik. Vergelyk byvoorbeeld die benutting van die Shattertipe letter uit die groep Manual (vgl. die indeling van lettertipes deur Evans, 1988:158-161). Grobbelaar 
en Jordaan (1980:34-35) illustreer die gevoelswaarde van die lettertipe deur die woord "skree" in Shatter aan te bied (hierby afgedruk). Met verwysing na die gevoelswaarde sê Evans (1988:161) dat Shatter nie "... the easiest of faces [is] to read, but it projects a forceful set of shock and suspense. It would be ideal for the headline titling of a psycho-movie".

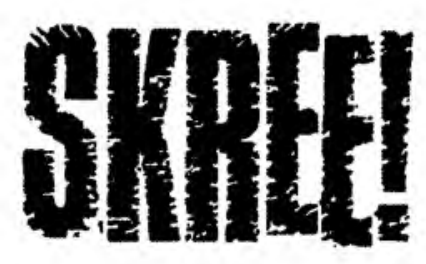

Die opmerking van Evans oor die emosionele waarde van letters herinner aan die lettristiese oortuiging dat die individuele letter emosioneel gelaai is. Ook Appollinaire het die emosionele krag van letters beklemtoon toe hy in sy teorie oor die ideogram gesuggereer het dat die alfabet geskikter is om gevoel oor te dra as 'n visuele afbeelding (vgl. Seaman, 1981:201-228).

So is die sogenaamde Gotiese letters, wat volgens Evans (1988:161) nie die regte benaming is nie, geplaas in die groep Black Letter. Langenhoven het iets van die gevoelswaarde van die skrifbeeld begryp toe hy 'n fragment van 'n antieke partituur van 'n gewyde lied (Langenhoven, 1921:97) in sy lang epiese gedig "Eerste skoffies op die pad van SuidAfrika" laat afbeeld het.

Die magiese krag van skrif kan waarskynlik toegeskryf word aan die feit dat 'n klein aantal geletterdes of ingewydes (gewoonlik priesters) in die antieke tyd die vermoë en voorreg gehad het om betekenis aan skrif te gee. Die assosiasie van die Gotiese lettertipes met die vroeë boekdrukkuns, asook met die ou musieknotasie, verleen 'n argivale voorkoms aan die teks van Langenhoven. lets van 'n geheimsinnige krag word nog in die sierlike, maar moeilik leesbare letters ervaar.

Daar is voorts voorbeelde van die benutting van groot- en vetdrukletters by digters soos Dan Roodt, Hein Viljoen, Johan van Wyk en andere. 'n Opvallende mengselgebruik kom voor in Wopko Jensma se gedig "caTaToniA" - die "gedig" dwing die leser om visueel daarvan kennis te neem. Verder is daar die gebruikmaking van skuinsdruk of kursief binne poëtiese tekste met as belangrike funksies die kontrastering en isolasie van teksgegewens. 
Leestekens word ook op verskeie wyses visueel benut. In sommige tekste domineer die leestekens. In "Konsertina-poskaar" van D.J. Opperman (1964:48) word woorde deur koppeltekens aan mekaar verbind om ' $n$ visuele skrifuitbeelding van 'n konsertinaposkaart te bewerkstellig.

\section{Funksies van fisionomiese opvallendhede in Afrikaanse gedigte}

Die opvallende fisionomie wat digters in sommige gedigte skep, hou verband met die drang na doeltreffende of optimale kommunikasie. Daar word aanhoudend na kommunikasiewyses gesoek wat anders is as dié in die konvensionele (Afrikaanse) gedig. Uit die enkele gedigte wat bespreek is, is dit duidelik dat 'n verskeidenheid kommunikatiewe effekte deur opvallende fisionomiese tegnieke bereik kan word.

Die fisionomies opvallende is ' $n$ wins in die Afrikaanse poësie vanweë die direkte kommunikasie en die bewusmaking van die taal wat bewerkstellig word, asook die dikwels onvertaalbare, gekonsentreerde mededeling wat bewerk word.

Uit die korpus bestaande fisionomies opvallende gedigte in Afrikaans is enkele voorbeelde geselekteer om konkretiserings of fisionomiese opvallendheid aan te dui. Fisionomie lê origens op nog baie meer vlakke as wat hierbo geselekteer is. Nie alleen die woord word fisionomies benut nie, maar ook die versreël, die sin en die strofe - ja selfs die wit en die breedte van die kantlynruimtes. Die meerdere of mindere mate waarin 'n gedig fisionomies aangebied word, hou nie noodwendig verband met die meerdere of mindere trefkrag of ' $n$ beter of swakker gehalte van 'n gedig nie. Met hierdie artikel is eerder die terrein van die fisionomie in die Afrikaanse poësie bekendgestel sonder dat 'n eksplisiete oordeel oor die waarde van die betrokke gedigte uitgespreek is.

\section{Bibliografie}

Anon. 1976. Menkent. (In: Grote Larousse encyclopedie, 16:168.)

Boshoff, Willem. 1980. Kykafrikaans. Johannesburg : Pannevis.

Brems, H. 1984. Raakpunten tussen Nederlandse poézie en beeldende kunst sinds 1945. Deel 2. Ons erfdeel, 27(2):179-187, Feb.

Breytenbach, Breyten 1964 (1974-druk). Die ysterkoei moet sweet. Doornfontein, Johannesburg : A.P.B.

Cillié, G.G. 1981. Geskiedenis van die sterrekunde. (In: Nuwe Afrikaanse kinderensiklopedie 5:[166]-213.)

Cloete, T.T. 1980. Poesie. In: Cloete, T.T. (red.) Die Afrikaanse literatuur sedert Sestig. Goodwood : Nassou. p. 115-317.

Cloete, T.T. 1985 Allotroop. Kaapstad : Tafelberg. 
Clüver, C. 1982. Reflections on verbivocovisual ideograms. Poetics Today, 3(3): [137]-147, Summer.

Crystal, D. 1987. The Cambridge encyclopedia of language. Cambridge : Cambridge University Press

De Vree, P. (1981). Historiek en overzicht van de konkrete poëzie. In: De Vree, P. Paul de Vree: [tentoonstelling] Provinciaal Museum Hasselt, 19.9/8.11.1981. [Hasselt : Provinciaal Museum.] (Fotokopie.) p.[1]-[2].)

De Vree, P. [1970]. Over visuele poezie. In: Amsterdam (Nederlande). Stedelijk Museum. Klankteksten, konkrete poezie, visuele teksten? [Tentoonstelling. Amsterdam : Die Museum.] (Stedelijk Museum Amsterdam. Catalogus: no. 42.) (Fotokopie.). p. 9-14.)

Dekker, G. 1965. Inleiding. In: Visser, A.G. Bloemlesing uit die gedigte van A.G. Visser. Keuse en inleiding van G. Dekker. 7de dr. Pretoria : Van Schaik. p. $\mathbf{x}$.

Du Plessis, Phil. 1971. Geskrifte om 'n houtgesig, 1965-70. Kaapstad: Tafelberg.

Evans, R.B. 1988. Production and creativity in advertising. London : Pitman.

Geggus, R. 1961. Die wit in die poësie: 'n ondersoek na die funksionaliteit van die wit in die visuele aanbod van hedendaagse poësie. Amsterdam : Heijnis. 142 p. (Ook as proefskrif uitgegee.)

Greyling, A. 1979. Verskeidenheid en samehang in Opperman se Komas. Die Vaderland, 60:1, April, 21.

Grobbelaar, Pieter W. \& Jordaan, Willem. 1980. 'n Bietjie baie bogtery: die groot Afrikaanse knutselboek. Kaapstad : Tafelberg.

Hambidge, Joan. 1987. Die anatomie van melankolie. Kaapstad: Human \& Rousseau.

HAT

kyk Schoonees, P.C., Swanepeol, C.J., Du Toit, S.J. \& Booysen, C.M. (reds.) 1979. HAT: verklarende handwoordeboek van die Afrikaanse taal vir universiteit, skool, huis en kantoor. Doornfontein, Johannesburg : Perskor.

Hugo, D.J. 1988. Die digter en sy middele ' $n$ ondersoek na die vernufpoèsie in Afrikaans. Bloemfontein : UOVS. (D.Litt.-proefskrif.) (Mikrofiche.)

Jonckheere,W.F. 1989. Die beeldgedig as genre. Tydsknif vir Geesteswetenskappe, 29(4):269-278, Des.

Jonckheere,W.F. 1990. Die beeldgedig as genre. Tydsknif vir Geesteswetenskappe, $30(1): 1-15$, Maart.

Langenhoven, C. J. 1921. Eerste skoffies op die pad van Suid-Afrika. Tekeninge van Reenen J. van Reenen. Kaapstad : Nas. Pers.

Malan, R. 1986. Komas uit 'n bamboesstok van D.J. Opperman en die strukturalistiese konsep van intertekstualiteit. Johannesburg : RAU. (D. Litt. et Phil.- proefskrif.)

Mischke, Carl. 1984. Interme weerstand. Kaapstad : Human \& Rousseau.

Opperman, D.J. 1964. Kuns-mis. 1947-64. Kaapstad : Human \& Rousseau.

Opperman, D.J. 1979. Komas uit 'n bamboesstok: synde die mirakelagtige terugkeer ná lewerversaking van ene Marco Polo ... Kaapstad : Human \& Rousseau. 20 $\mathrm{cm}$.

Opperman, D.J. 1979a. Komas uit 'n bamboesstok: synde die mirakelagtige terugkeer ná lewerversaking van ene Marco Polo ... Kaapstad : Human \& Rousseau. $31 \mathrm{~cm}$.

Pignatari, D. 1982. Concrete poetry: a brief structural-historical guideline. Poetics Today, 3(3):[189]-195, Summer.

Reinecke, C.S. 1991. Fisionomies opvallende poësie in Afrikaans. Potchefstroom: $\mathrm{PU}$ vir $\mathrm{CHO}$. (Ph.D.-proefskrif.) 
Sauer, M. 1982. Kunswerke van klei, glas en metaal. (In: Nuwe Afrikaanse kinderensiklopedie, 5:[183]-201.)

Schoonees, P.C. \& Toerien, M.F. (reds.) 1955. Woordeboek van die Afrikaanse taal. Tweede deel, D-F. Pretoria : Staatsdrukker.

Schoonees, P.C., Swanepoel, C.J., Du Toit, S.J. \& Booysen, C.M. (reds.) 1979. HAT: verklarende handwoordeboek van die Afrikaanse taal vir universiteit, skool, huis en kantoor. Doornfontein, Johannesburg : Perskor.

Seaman, D.W. 1981. Concrete poetry in France. Ann Arbor, Mich. : UMI Research Press. (Studies in Fine Arts, The avant-garde: no 18.)

Smit, Pieter. 1977. Visum vir die vreemde. Kaapstad: Tafelberg.

Taylor, C.A. 1985. A poetics of seeing: the implications of visual form in modern poetry. New York : Garland. (Garland publications in comparative literature.)

Toerien, Barend J. 1983. "KONKRETE POëSIE". Stet, 2(1):17, Des.

Van Wyk, Johan. 1976. Deur die oog van die luiperd. Kaapstad : Human \& Rousseau.

Visser, A.G. 1927. Rose van herinnering en ander gedigte. Pretoria : Van Schaik. WAT

kyk Schoonees, P.C. \& Toerien, M.F. (reds.) 1955. Woordeboek van die Afrikaanse taal. Tweede deel, D-F.

\section{Kernbegrippe:}

visueie poësie

kykpoësie

konkrete poësie

fisionomie

ideogram

fonogram

hiëroglief

Key concepts:

visual poetry

concrete poetry

physionomy

ideogram

phonogram

hieroglyph 
